\title{
ANALYSIS OF THE LOCATION OF NANNING LARGE-SCALE MALL BASED ON BP NEURAL NETWORK
}

\author{
Han Huang ${ }^{1,2}$, Lilong Liu ${ }^{1,2, *}$ \\ ${ }^{1}$ College of Geomatic Engineering and Geoinfomatics, Gulin University of Technology, Gulin, 541004, China \\ ${ }^{2}$ Guangxi Key Laboratory of Spatial Information and Geomatics, Guilin, 541004, China
}

KEY WORDS: large-scale mall, geographic information system, matlab, location, BP neural network, Nanning City

\begin{abstract}
:
Site selection is a key first step in the operation of large-scale shopping malls, and most of the existing site selection methods lack practicality and efficiency. Therefore, it is necessary to carry out a scientific modeling of the site selection problem and provide effective reference information for site selection. With the development of machine learning algorithms, the modeling of such problems becomes more and more simple. In this paper, using matlab software as a tool, based on BP neural network algorithm, Nanning urban area is selected as the research object. After analyzing the influencing factors of location problem, the large-scale mall location analysis modeling is carried out. After repeated training and testing of the training data and the test data, the data for testing the usability is input into the model and applied for analysis. It turns out that the large-scale mall location analysis model is usable and can meet the site selection needs of the mall.
\end{abstract}

\section{INTRODUCTION}

With the new goal of the development of the party and state undertakings put forward by the 19th National Congress, China has begun a new journey of building a socialist modernized country. A modern country needs a modern city. Building a socialist modern country is also building a modern city. In every modern city, the most iconic is the large-scale shopping mall with diverse content. The large-scale shopping mall not only provides leisure and entertainment for the citizens and tourists, but also provides shopping opportunities for the city. Therefore, it is necessary to build a large-scale shopping mall with longterm good operation in the city.

There is a famous saying in the commercial real estate industry, "The first condition for commercial success is site selection, and the second condition is site selection." For large-scale shopping malls, facility location is the starting point for its strategic decision-making and is a key factor affecting the efficiency of the mall. China has been very particular about building sites since ancient times, but unfortunately, the traditional method of site selection is inevitably out of the needs of the masses in today's scientific and efficient environment. Recently, there have been some site selection methods for quantitative and comprehensive scoring of site selection factors, which have considerable reference functions. However, the composite score does not take into account the weighting ratio between the factors, and it reduces the practicality of such methods.

The development of artificial neural network algorithms makes it no longer difficult to build models to deal with such problems Combined with the geographical data obtained by GIS processing, the artificial neural network is set after each location factor is obtained. After training, a usable location model can be obtained.

\section{T LARGE SHOPPING MALL LOCATION}

\subsection{Large shopping mall location principle}

The purpose of the large-scale shopping mall is to choose a good location for the establishment of the mall. As the development of modern cities becomes more and more rapid, the competition in the market economy becomes fierce. In this context, the mall needs to maintain good business and economic benefits in order to compete in the advantage. In order to maximize economic benefits, it is necessary to consider the location, environment, transportation, consumer demand and other factors around the mall before the mall is established. According to the economic benefits pursued by the mall, the principle of site selection for large-scale shopping malls should have three directions:

1.Convenience: convenient transportation around the mall; 2.Competitiveness: There are no similar malls around, considering the impact of competition;

3.Stability: There are enough residential areas in the radiation area of the mall to ensure a stable source of consumers.

\subsection{Factors affecting the location of large-scale shopping malls}

There are various factors to be considered in the site selection of the mall, of which there are four main aspects:

1.Traffic factors: Whether it is the customer's request for convenient access or the demand for goods transportation by the store, the mall needs a convenient traffic environment.

2.Demographic factors: The primary function of the mall is to meet the residents' demand for shopping. This requires a certain number of residents in the service radiation area of the mall.

3.Parking factors: Vehicles have gradually become an essential means of transportation in the public's home. The mall should also provide parking lots, or choose an address with other parking spaces around it.

*Corresponding author. hn-liulilong@163.com. 
4.Competitive factors: Similar to existing large-scale similar malls, it will lead to vicious competition, so it is best to avoid it.

\section{ARTIFICIAL NEURAL NETWORKS}

Artificial Neural Network (ANN) is a neural network (NN), which is an operational model that abstracts the human brain neural network from the perspective of information processing. It is actually a complex network with a large number of simple components connected to each other, with a high degree of nonlinearity, a system capable of complex logical operations and nonlinear relationships.

\subsection{Artificial neuron structure}

An artificial neural network is an artificial network composed of a large number of processing units that are interconnected to simulate the structure and function of the brain nervous system. These processing units are called artificial neurons. The artificial neuron structure is shown below:

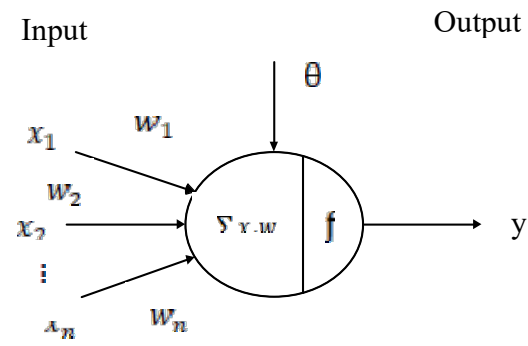

Figure 1. Artificial neuron structure

For a certain neuron, let the information from other neurons $i$ be $x_{i}$, and the interaction strength between them and the processing unit is the connection weight of $w_{i}, \mathrm{i}=0,1, \ldots, \mathrm{n}-1$, processing unit The internal threshold is $\theta$. Then the input of this neuron is:

$$
\sum_{i=0}^{n-1} w_{i} x_{i}
$$

The output of the processing unit is:

$$
y=f\left(\sum_{i=0}^{n-1} w_{i} x_{i}-\theta\right)
$$

Where $x_{i}$ is the input of the i-th element, and $w_{i}$ is the interconnect weight of the $\mathrm{i}$-th processing unit and the processing unit, $f$, the neuron connection weight. A nickname is an activation function or an action function that determines the output of a node (neuron). $\theta$ represents the threshold of the hidden layer neural node.

\subsection{Artificial neuron activation function}

In neural networks, the ability and efficiency of a network to solve problems depends not only on the network structure, but also on the activation function used by the network. The choice of the activation function has a greater impact on the convergence speed of the network. The selection of the activation function should be different for different practical problems.

The law that a neuron produces an output signal under the input signal is given by the neuron function Function, also known as the activation function, or transfer function, which is an external characteristic of the neuron model. It contains the process from the input signal to the net input, to the activation value, and finally to the output signal. Combines the role of net input and $f$ function. The $f$ functions are diverse in form, and their different characteristics can be used to form neural networks with different functions.

Commonly used activation functions come in the following forms:

1. Threshold function: This function is also commonly referred to as a step function. When the activation function uses a step function, the artificial neuron model is the MP model. At this time, the output of the neuron takes 1 or 0 , which reflects the excitation or inhibition of the neuron.

2.Linear function: This function can be used as the activation function of the output neuron when the output result is arbitrary. However, when the network is complex, the linear activation function greatly reduces the convergence of the network, so it is generally less used.

3. Logarithmic sigmoid function: The output of the logarithmic sigmoid function is between 0 and 1 , and is often required to be selected for signals with a range of 0 to 1 . It is the most widely used activation function in neurons.

4.Hyperbolic tangent sigmoid function: The hyperbolic tangent sigmoid function is similar to the smoothed step function, the shape is the same as the logarithmic sigmoid function, symmetric with the origin, and its output is between -11 , often required Output signals in the -11 range are selected.

\subsection{BP neural network concept}

BP neural network is a multi-layer feedforward neural network. Its main features are: the signal is forward propagating, and the error is backpropagating. The process of BP neural network is mainly divided into two stages. The first stage is the forward propagation of the signal, from the input layer through the hidden layer, and finally to the output layer. The second stage is the back propagation of the error, from the output layer to the hidden layer. The layer is included, and finally to the input layer, which adjusts the weight and offset of the hidden layer to the output layer, and the weight and offset of the input layer to the hidden layer.

A neural network includes an input layer, a hidden layer (intermediate layer), and an output layer. The number of neurons in the input layer is the same as the dimension of the input data. The number of neurons in the output layer is the same as the number of data to be fitted. The number of neurons in the hidden layer and the number of layers need to be designed by the designer according to some rules and objectives. To set. Before the advent of deep learning, the number of layers of the hidden layer is usually one layer, that is, the commonly used neural network is a three-layer network.

\subsection{BP network input and output relationship}

The transfer function used by the BP network is a nonlinear transformation function - the Sigmoid function (also known as the $\mathrm{S}$ function). Its characteristic is that the function itself and its derivatives are continuous, so it is very convenient in processing. The $\mathrm{S}$ function has two types: a unipolar S-type function and a bipolar S-type function. The unipolar S-type function is defined as follows:

$$
f(x)=\frac{1}{1+e^{-x}}
$$


Bipolar S-type function:

$$
f(x)=\frac{1-e^{-x}}{1+e^{-x}}
$$

When using the S-type activation function, type:

$$
\text { net }=x_{1} w_{1}+x_{2} w_{2}+\cdots+x_{n} w_{n}
$$

Output:

$$
y=f(n e t)=\frac{1}{1+e^{-n e t}}
$$

The derivative of the output:

$$
f^{r(\text { net })}=\frac{1}{1+e^{-n e t}}-\frac{1}{\left(1+e^{-n e t}\right)^{2}}=y(1-y)
$$

According to the $\mathrm{S}$ activation function there are:

When net is at $-5 \sim 0$, the value of the derivative is positive, and the value of the derivative is gradually increased, indicating that $\mathrm{f}(\mathrm{x})$ is getting larger and larger at a faster rate; the net is at $0 \sim 5$. The value of the derivative is positive, and the value of the derivative gradually decreases, indicating that $\mathrm{f}(\mathrm{x})$ is gradually getting larger. However, the speed of getting bigger is getting slower and slower. To train the neural network, we should try to control the value of net as much as possible within the range of faster convergence.

\section{ESTABLISHMENT OF LARGE-SCALE SHOPPING MALL LOCATION MODEL}

\subsection{Thoughts on establishing location model by using BP neural network}

In the process of establishing a location model using BP neura network, some shopping mall samples with interference effects should be excluded first, such as some malls with special geographical locations that cannot be replaced. Through the screening of the mall sample, the first step to optimize the BP neural network model is achieved.

In the process of establishing the location model, the basic idea is to input the influencing factors of the site selection into the neural network, and then use the comprehensive operational effect index of the mall as the output, and use the neural network to establish the influencing factors of the site selection and the operation effect of the mall. The nonlinear relationship between them. In this model, the existing mall sample input network is used to conduct BP neural network learning training to form a stable network structure.

\subsection{Establishment of BP neural network location model}

Establishing BP neural network model is to determine the network structure and the number of network neurons. Reasonable network structure is an important foundation for establishing BP neural network model. The main steps are: determining the input influence factor of the network, determining the network output, determining the BP network structure, determining the training data to train the network, testing the neural network using the test data, and denormalizing the data and error analysis.

\section{Determine the network input impact factor}

According to the analysis of the factors affecting the location selection of large-scale shopping malls, this paper will adopt four factors, namely population factor, parking factor, competition factor and traffic factor, as the input layer of neural network: population density, parking lot quantity, competition mall The quantity, the number of roads, the impact factor and its description are shown in Table 1.

This model takes a large-scale shopping mall that radiates to the suburbs in the center of Nanning as a sample, and establishes an

\begin{tabular}{|c|c|c|}
\hline Influencing factors & impact factors & $\begin{array}{l}\text { selection } \\
\text { instructions }\end{array}$ \\
\hline Population factor & $\begin{array}{c}\text { A population } \\
\text { density }\end{array}$ & $\begin{array}{c}\text { Site population } \\
\text { density }\end{array}$ \\
\hline Parking factor & $\begin{array}{l}\text { B Number of } \\
\text { parking lots }\end{array}$ & $\begin{array}{l}\text { Number of parking } \\
\text { spaces within } 2 \mathrm{~km}\end{array}$ \\
\hline $\begin{array}{l}\text { Competitive } \\
\text { factors }\end{array}$ & $\begin{array}{l}\text { C number of } \\
\text { competitive }\end{array}$ & $\begin{array}{l}\text { Malls } 2 \mathrm{~m} \text { of } \\
\text { existing malls } \\
\text { within } 2 \mathrm{~km}\end{array}$ \\
\hline Traffic factors & D Number of roads & $\begin{array}{l}\text { Number of roads } \\
\text { within } 2 \mathrm{~km}\end{array}$ \\
\hline
\end{tabular}
analysis model for the factors affecting the location of largescale shopping malls in Nanning. Some sample data tables are shown in Table 2.

\begin{tabular}{|c|c|c|c|c|}
\hline & $\mathrm{A}$ & B & $\mathrm{C}$ & $\mathrm{D}$ \\
\hline $\begin{array}{l}\text { Vientiane } \\
\text { City }\end{array}$ & 5 & 4 & 3 & 3 \\
\hline $\begin{array}{l}\text { Jiangnan } \\
\text { Wanda } \\
\text { Plaza }\end{array}$ & 4 & 3 & 2 & 4 \\
\hline $\begin{array}{l}\text { Exhibition } \\
\text { and } \\
\text { navigation } \\
\text { ocean city }\end{array}$ & 3 & 5 & 1 & 5 \\
\hline $\begin{array}{l}\text { Fangyuanhui } \\
\text { Convention } \\
\text { and } \\
\text { Exhibition } \\
\text { Center }\end{array}$ & 3 & 5 & 1 & 3 \\
\hline $\begin{array}{l}\text { Chaoyang } \\
\text { Square }\end{array}$ & 5 & 5 & 5 & 5 \\
\hline
\end{tabular}

Table 1. Influencing factors and selection of large-scale shopping malls

Table 2. Partial Mall Sample Data Sheet

The population density data of the impact factors were obtained according to the density distribution of the population population of Nanning. The parking lot quantity data and the number of competitive shopping malls were obtained according to the 2015 Nanning service industry distribution map. The population density and road quantity data are divided into 5 levels. The higher the value, the higher the level.

\section{Determine the network output}

The operation of large-scale shopping malls, such as passenger flow and number of shops, can represent the success of site selection. Therefore, BP neural network output can be defined as the operation of large-scale shopping malls. Considering the characteristics of data and the main means of domestic retail evaluation, this paper uses the weighting value of Nanning Mall's score, number of ratings and number of shops on the public comment website as the evaluation criteria for the 
operation of large-scale shopping malls. The public comment scores 1 point and scores 1 point, score 5 points is 5 ; the number of shops below 20 points is 1 point, the number of points above 200 is 5 points; the score number is 10 points for 1 point, and 200 points for 5 points. The details are shown in Table 3 .

\begin{tabular}{|l|ll|l|l|}
\hline Mall Rating & $\begin{array}{l}\text { Number of } \\
\text { Shops }\end{array}$ & $\begin{array}{l}\text { Number of } \\
\text { people rated }\end{array}$ & Score \\
\hline 5 & $200+$ & $200+$ & 5 \\
4.5 & $150+$ & $100+$ & 4 \\
4 & $100+$ & $50+$ & 3 \\
3.5 & $50+$ & $30+$ & 2 \\
$3-$ & $20-$ & $10-$ & 1 \\
\hline
\end{tabular}

Table 3. Output rating specific criteria

According to the characteristics of the data obtained by this modeling, the three factor weighted scores of the scoring standard are used as the evaluation criteria of the final site selection adaptability, and the location suitability level is divided. The higher the score, the better the address suitability; The score $\mathrm{S}>6$ is very suitable; $5 \leqslant \mathrm{~S} \leqslant 4$, which is suitable; $3 \leqslant$ $\mathrm{S}<4$, which is less suitable; $\mathrm{S}<3$, is unsuitable.

\section{Determine the BP network structure}

According to the sample data characteristics and evaluation criteria of Nanning Mall, combined with the application research of BP neural network in the field of location, this paper chooses to establish a three-layer BP neural network structure, which is input layer, hidden layer and output layer. The number of neurons in the input layer is 4 , and the number of neurons in the output layer is 1 . The determination of the number of hidden layer nodes is related to the complexity of the problem to be solved and the case of the sample data. For the three-layer BP neural network, the calculation formula of the hidden layer node $\mathrm{s}$ is generally:

$$
s=\sqrt{n+m}+a
$$

Where $\mathrm{n}$ is the number of input nodes, $\mathrm{m}$ is the

number of output nodes, and a is a natural number between 1-10. Therefore, the number of hidden layers can be any number between 3 and 12 .

In this paper, BP neural network error back propagation algorithm is used to conduct network neural training experiments. The learning rate of the network is 0.03 , the target error is $10^{-3}$, and the number of training is 2000 . After multiple network training, different hidden layer nodes are obtained. The network error corresponding to the number, Table 4 is the case of the training error corresponding to the number of different hidden layers.

\begin{tabular}{|l|l|l|}
\hline $\begin{array}{l}\text { Number of hidden } \\
\text { layers }\end{array}$ & \multicolumn{2}{|l|}{ reaching the target } \\
value & training \\
times & actual error \\
\hline 3 & 2000 & 0.009537 \\
4 & 2000 & 0.008467 \\
5 & 1478 & 0.000982 \\
6 & 1552 & 0.000946 \\
7 & 1467 & 0.000821 \\
8 & 1334 & 0.0008158 \\
9 & 1378 & 0.0008197 \\
10 & 1445 & 0.0008203 \\
11 & 1821 & 0.0008204 \\
12 & 2000 & 0.001079 \\
\hline
\end{tabular}

Table 4. Network training situation table with different number of hidden layer nodes
According to the data in Table 4, it can be found that when the number of hidden layer nodes is 8 , the network has the smallest training error and the least number of network training. Therefore, it is determined that the number of hidden nodes in the BP neural network is 8 in this paper, and the topology of the BP neural network is finally determined to be a $5 \times 8 \times 1$ threelayer network structure.

\subsection{MATLAB implements BP neural algorithm}

MATLAB has complete graphics processing function, friendly user interface and natural language close to mathematical expressions. The built-in neural network toolbox allows users to adjust various settings and build ideal models in BP neural network modeling. The theoretical basis of MATLAB's built-in neural network toolbox is artificial neural network theory. With the MATLAB language, a suitable activation function is constructed in the network output layer. When the input sample data is passed to the output layer, the neural network automatically completes the use of the activation function.

In this paper, MATLAB is used to program the neural network. In the neural network training process, the training data in the required samples is set to 25 groups, the test data is 10 groups, and the samples are normalized. The activation function selected by BP neural network in training is tansig, the maximum number of training is 2000 , the learning rate is 0.3 , and the error precision is 0.001 . Some key codes are as follows:

[p_train, $\mathrm{ps}$ _input $]=\operatorname{mapminmax}\left(\mathrm{P}_{-}\right.$train $\left., 0,1\right) ; \%$ Data normalization

p_test $=$ mapminmax ('apply',P_test,ps_input $)$;

[t_train, ps_output] $=\operatorname{mapminmax}(\mathrm{T}$ _train $, 0,1)$;

net $=$ newff $\left(p_{\text {_train, }}\right.$ _t train, 9$) ; \%$ Create a network

net.trainParam.epochs $=1000 ; \%$ Set training parameters

net.trainParam.goal $=1 \mathrm{e}-2$;

net.trainParam. $1 \mathrm{r}=0.3$;

net $=$ train(net,p_train,t train);

$\mathrm{t} \_\operatorname{sim}=\operatorname{sim}\left(\right.$ net, $\mathrm{p}_{-}$test $) ; \%$ Simulation test

T_sim = mapminmax('reverse',t_sim,ps_output); \% Data denormalization

error $=$ abs $\left(T_{-}\right.$sim $-T_{-}$test $) . / T \_$test; \% Performance evaluation $\mathrm{R} 2=\left(\mathrm{N} * \operatorname{sum}\left(\mathrm{T} \operatorname{sim}{ }^{-} * \mathrm{~T} \text { test }\right)-\operatorname{sum}(\mathrm{T} \operatorname{sim}) * \operatorname{sum}(\mathrm{T} \text { test })\right)^{\wedge} 2$ $/\left(\left(\mathrm{N} * \operatorname{sum}\left(\overline{(T} \_\operatorname{sim}\right) \cdot{ }^{\wedge} 2\right)-\left(\operatorname{sum}\left(\bar{T} \_\operatorname{sim}\right)\right)^{\wedge} 2\right) *(\mathrm{~N} *$ $\operatorname{sum}\left(\left(T_{-}\right.\right.$test $\left.\left.\left.) . \wedge 2\right)-(\operatorname{sum}(T \text { test }))^{\wedge} 2\right)\right)$;

result $=\left[T_{-}\right.$test' $T_{-}$sim' error' $]$

\subsection{Modeling Accuracy Analysis and Neural Network Application analysis}

Run the neural network toolbox in the MATLAB software to obtain the model fitting results. After further adjustment, the fitted curve is closer to the prediction curve of the test data set. Once the ideal model is obtained, the final neural network application analysis can be performed. The data used to test the neural network location application is entered in the established network neural and the resulting output is compared to the specified target output. The test data is shown in Table 5. 


\begin{tabular}{|c|c|c|c|c|c|}
\hline Test point & $\begin{array}{l}\text { A } \\
\text { population }\end{array}$ & $\begin{array}{l}\text { B } \\
\text { parking } \\
\text { lot }\end{array}$ & $\begin{array}{l}\text { C } \\
\text { competitor }\end{array}$ & $\begin{array}{l}\mathrm{D} \\
\text { road }\end{array}$ & $\begin{array}{l}\text { actual } \\
\text { score }\end{array}$ \\
\hline $\begin{array}{l}\text { Dream } \\
\text { Island } \\
\text { Department } \\
\text { Store } \\
\text { (Jiangnan } \\
\text { Branch) }\end{array}$ & 4 & 1 & 3 & 3 & 4 \\
\hline $\begin{array}{l}\text { Ocean } \\
\text { Shopping } \\
\text { Plaza } \\
\text { (Friendly } \\
\text { shop) }\end{array}$ & 5 & 1 & 4 & 2 & 3 \\
\hline $\begin{array}{l}\text { Green } \\
\text { Square } \\
\text { Central } \\
\text { Square }\end{array}$ & 4 & 2 & 1 & 4 & 4 \\
\hline
\end{tabular}

Table 5. Test data sheet

After inputting the test data, the input of the neural network is: 4 3,4 , and the score of the predicted output should be $4,3,5$. The error of the suitability score $\mathrm{S}$ is only 1 when the green square central square data is output.

On the map, Dream Island Department Store (Jiangnan Store) is located near the railway station, the traffic is relatively convenient but there are many competitors, and most of the surrounding population is a floating population, so the site selection can only be considered appropriate; Ocean Shopping Center (Friendly Shop) ) It is not suitable for the university towns, so there are more competitors, and because the roads are poor due to poor road planning near the university town, the site selection should be inappropriate. The Central Plaza of Greenland is located near the Wanda Commercial District in Qingxiu District. Although it has a competitive relationship with Wanda, it has an ideal geographical location. The competition with Wanda also promotes the development of the two, so it is more suitable.

In summary, the evaluation results of the test data are basically in line with the actual business situation. Therefore, the neural network modeling has usability, and it can predict the accuracy of the large-scale shopping site in Nanning.

\section{CONCLUSION}

The issue of location selection for large-scale shopping malls is of great importance and is a problem that every operator needs to carefully consider. The ideal location of the mall is the first step of the operation of the mall. In order to solve this problem, this paper takes the urban area of Nanning as the research object, analyzes the influencing factors of the location of the mall, and uses the neural network as a tool to conduct an evaluation experiment. verification. At the end of the neural network modeling, three Nanning city mall locations were selected as test data to evaluate the model's prediction results. Facts have proved that the large-scale shopping mall location analysis model can better complete the analysis of the location selection of large-scale shopping malls in the urban area of Nanning, and provide services for the future location of large-scale shopping malls.

\section{ACKNOWLEDGEMENTS}

This work was sponsored by the National Natural Foundation of China(41664002;41704027); Guangxi Natural Science Foundation of China (2018GXNSFAA294045; 2017GXNSFDA198016; 2017GXNSFBA198139); the "Ba Gui Scholars" program of the provincial government of Guangxi; and the Guangxi Key Laboratory of Spatial Information and Geomatics (14-045-24-10;16-380-25-01).The authors would like to thanks all those who criticize and suggest this article.

\section{REFERENCES}

Liu Haiqin, 2017. Research on location selection of economical hotels based on GIS and artificial neural network[D]. China University of Mining and Technology,

David Malone, 2018. Former shopping mall becomes mixeduse urban complex in Beijing $[J]$. Building Design \& Construction.

Gopal Das,Geetika Varshneya, 2017. Consumer emotions: Determinants and outcomes in a shopping mall[J]. Journal of Retailing and Consumer Services, 38.

Abrudan Ioana N.,Dabija Dan Cristian, 2009.THE LIFE CYCLE OF SHOPPING CENTERS AND POSSIBLE REVITALIZATION STRATEGIES[J]. Annals of the University of Oradea : Economic Science,4(1).

Zhang Wei, Wang Shuai, Zhao Jia, Li Ya, 2009. Micro-location study of large-scale shopping malls in the suburbs of Beijing- Based on the analysis of Yansha Mall Yanshaqiao Store, OUTLETS Store and Jinyuan Store [J]. Capital Normal University Journal (Natural Science Edition), 2009, 30 (05): 8692.

Gao Wei, 2003. Principles and simulation examples of artificial neural networks. Mechanical Industry Press.

Zhou Zhihua, 2004. Neural Network and Its Application. Tsinghua University Press.

Lun Lun, 2001. Geographic Information System. Tsinghua University Pess. 